\section{The mitochondria and cellular calcium}

SIR - Somlyo's News and Views article ${ }^{1}$ summarized evidence that the regulation of intracelluar free calcium level by the sarcoplasmic reticulum in muscle may be carried out by the endoplasmic reticulum in nonmuscle cells. I believe the subsidiary role accorded to the mitochondria in this presentation fails to give due weight to recent advances in the study of their $\mathrm{Ca}$ transport. Newer work shows two important features. First, in contrast to the earlier results with the isolated organelles, both $\mathrm{Ca}$ affinity and uptake rate are sufficient to predict mitochondrial involvement in intact cell $\mathrm{Ca}$ regulation. Second, such regulation can be demonstrated in suspensions of mildly disrupted cells leaving the mitochondria in situ with activity observed under very near physiological conditions (see refs 2,3 for reviews). These comments do not detract from the role for the endoplasmic reticulum and sarcoplasmic reticulum in cellular $\mathrm{Ca}$ homeostatis summarized by Somlyo, but allow for interactions between organelles particularly in dynamic aspects of Ca-regulation.

One paper specifically cited in Somlyo's article (ref. 4) as negative evidence for a mitochondrial involvement in $\mathrm{Ca}$-regulation merits discussion since much depends upon the precise detail. The $\mathrm{Ca}$-content of mitochondria in resting and activated smooth muscle was determined by electron probe microanalysis. It rose from $0.8 \pm 0.5$ mmol per kg dry wt to $1.8 \pm 0.6(n=61$; \pm s.e.m.) which was quite reasonably stated to be "not significant" (in the statistical sense; the $P$ value only approaches the 0.1 level). (Somlyo and his group have made exhaustive studies ${ }^{5}$ of the limitations of this technique.) In fact the wrong null hypothesis has been applied: since the authors wish to show that "Mitochondria do not accumulate significant $\mathrm{Ca}$ concentrations in normal cells" (the article's title), the data should be assessed for similarity rather than difference. On this basis the conclusion represented by the title would have to be rejected, even if the converse remains unproven. (Recently published revised data ${ }^{6}$ do not materially affect these comments.) A change of the order of $1 \mathrm{mM}$ in mitochondrial $\mathrm{Ca}$ would not be resolved reliably by this technique but would actually be sufficent to account for much of the Ca necessary to produce full relaxation of cardiac (and possibly smooth) muscle given the relative volumes occupied by the mitochondria in these tissues and the concentration of binding sites saturated during contraction ${ }^{7}$. Other negative evidence, to which Somlyo attaches significance, includes reports that $\mathrm{Ca}$-uptake rates and affinities are too low, particularly at physiological $\left[\mathrm{Mg}^{2+}\right]^{8}$. This evidence has been superceded; even the symposium papers $^{9-11}$ immediately preceding Somlyo's own contribution ${ }^{4}$ provide strong, positive evidence for the physio- logical role of the mitochondria. In particular, Becker ${ }^{11}$ demonstrates $\left[\mathrm{Ca}^{2+}\right]$ regulation at submicromolar levels by both isolated mitochondria and those accessed by selective (digitonin) perforation of the cell membrane under near physiological conditions.

These phenomena have recently been studied with selectively 'skinned' cardiac muscle either as myocyte suspensions (ion fluxes monitored with ion-sensitive electrodes ${ }^{12}$ ) or in trabeculae (force measurements ${ }^{13,14}$ ) under physiological conditions of $\left[\mathrm{Mg}^{2+}\right],\left[\mathrm{Na}{ }^{+}\right], p \mathrm{H}$, temperature and extramitochondrial $\mathrm{Ca}$-buffer capacity. 'Sarcoplasmic' $\left[\mathrm{Ca}^{2+}\right]$ reduction in the micromolar range by the mitochondria has an effective time constant below $200 \mathrm{~ms}$. Transfer of $\mathrm{Ca}$ from the mitochondria to the sarcoplasmic reticulum, as a result of their different $\mathrm{Ca}$-affinities and $\left[\mathrm{Na}^{+}\right]$ sensitivity, can occur between successive calcium releases from the reticulum. Thus $\mathrm{Ca}$ is only transiently accumulated by the mitochondria during relaxation. I believe that the evidence reviewed should keep minds open to the idea that the "complicated mitochondrial $\mathrm{Ca}$ transport system so passionately pursued by biochemists for more than 20 years" (ref.1, p.517) has physiological significance, and may be an integral part of the system responsible for cellular $\mathrm{Ca}$ regulation.

\section{DAVID J. Miller}

Institute of Physiology,

Glasgow University,

Glasgow G12 8QQ, UK

1. Somlyo, A.P. Nature 309, 516-517 (1984).

. Nicholls, D. \& Akerman, K. Biochim. biophys. Acta 683 $57-68$ (1982)

3. Carafoli, E. in Membrane Transport of Calcium (ed. Carafoli, E.) 109-139 (Academic, London, 1982).

4. Somlyo, A.P., Somlyo, A.V., Shuman, H. \& Scarpa, A. in Calcium and Phosphate Transport across Biomembrane (eds Bronnert, F.B. \& Peterlik, M.) 87-93 (Academic, New York, 1981).

5. Somlyo, A.P., Somlyo, A.V. \& Shuman, H. J. Cell Biol. 11, 316-335 (1979).

6. Bond, M. Schuman, H., Somlyo, A.P. \& Somlyo, A.V. J. Physiol. Lond. 357, 185-201 (1984).

Fabiato A. Am. J. Physiol 245, C1-C14 (1983).

8. Scarpa, A. \& Graziotti, P. J. gen. Physiol. 62, 756-772 1973)

9. Nicholls, D. \& Akerman, K. in Calcium and Phosphat Transport across Biomembranes (eds Bronner, F. \& Peterlik, M.) 83-86 (1981).

10. Becker, G.L. in Membrane Transport of Calcium (ed. Carafoli, E.) 79-82 (1982)

11. Lehninger, A.L., Fiskum, G., Vercesi, A. \& Tew, W. in Calcium and Phosphate Transport across Biomembranes (eds Bronnert, F. \& Peterlik, M.) 73-78 (1981).

12. Fry, C.H., Powell, T., Twist, V.W. \& Ward, J.P.T. Proc $R$. Soc. $B$ (in the press)

13. Harrison, S.M. \& Miller, D.J. J. Physiol., Lond. 353, 55P (1984)

14. Fry, C.H. \& Miller, D.J. in Control and Manipulation of Calcium Movement (ed. Parratt, J.) (Raven, New York, in the press).

\section{No pattern yet for snowflakes}

SIR - It surprises me that John Maddox's News and Views article ${ }^{1}$ makes no reference to the role of electric forces in determining the structure of snowflakes. Admittedly, short-range forces are implied by the surface tension effects considered but long-range forces are also likely to have an effect. One would expect that with a material of such high polarizability as water (dielectric constant 78) the electric field around charged ice crystals gathers water molecules at a far higher rate than would result from the random walks of neutral particles. The ice crystals will be charged by photoelectric emission, most of the ejected electrons being collected by water molecules. The photo-energy will be used in transporting the polarized molecules by electric attraction.

The initial ice crystals are long hexagonal prisms and growth will take place on the major faces, under suitable conditions, thus causing the hexagonal symmetry of the snowflakes. Electrical mutual repulsion between growths on separate faces will prevent them from coalescing to merely increase the growth of the nucleating prism. Possibly these crystals formed in darkness, uncharged, by the random walk process. There are many factors likely to influence the form of growth in addition to the very obvious; temperature and water content of the atmosphere. Air pollution of various kinds, turbulence and electric fields of large scale such as those which give rise to lightning may all have such effects. There is some evidence that long ice crystals may be aligned vertically by an electric field, under calm conditions ${ }^{2,3}$.

It is unclear to me why there should be any need to invoke lattice vibrations to "tell one growing face what the shape of the opposite growing face is like" 1 . It does not have 'the need to know'. In a statistically uniform environment of many particles, statistics and electric fields will shape all six growths uniformly.

W.S. MORTLEY

\section{Plantation Road,}

Boreham,

Chelmsford,

Essex CM3 3EA, UK

1. Maddox, J. Nature 313, 93 (1985)

2. Mortley, W.S. New Scient. S July, 47 (1979).

3. Watts B.C. New Scient. 19 July, 227 (1979).

SIR - The missing element for models of snowflake growth seems to be some property which could coordinate growth across a crystal. May I suggest that the unneutralized partial charges at the surface of the crystal may provide such a mechanism? In the case of proteins, unneutralized charge at the surface generates electrostatic fields through the interior of the molecule which affect protein structure elsewhere in the molecule. In the case of snowflakes, possibly comparable electrostatic fields could provide an attractive force at the minor axis, thus leading to greater crystal growth at the smaller diameters. Whether such a mechanism could account for crystal symmetry would depend on details of charge structure at the surface of the crystal and the permittivity of the interior.

Department of Biochemistry Alice FulTON

University of Iowa

Iowa City, Iowa 52242, USA 